Active transport adenosine triphosphatase erythrocyte potassium premature infant reticulocytosis sodium

\title{
Red Cell Stromal Adenosine Triphosphatase (ATPase) of Newborn Infants
}

\author{
June M. Whaun and Frank A. Oski ${ }^{[27]}$ \\ Department of Pediatrics, the Hospital of the University of Pennsylvania, \\ and the University of Pennsylvania School of Medicine, Philadelphia, Pennsylvania, USA
}

\section{Extract}

Erythrocytes of the newborn infant are known to lose potassium at a rapid rate during short periods of incubation. Net potassium loss can occur as a consequence of either increased leak or inadequate active influx in the presence of normal leak. This inadequate active influx may be associated with peculiarities in the properties of the cation transport process situated in the erythrocyte membrane. For this reason, red cell stromal ATPase, a membrane enzyme intimately involved in cation transport, was examined in the erythrocytes of fourteen normal adults, sixteen term infants, ten premature infants, and thirteen patients with reticulocytosis.

$\mathrm{Km}$ ATP was found to be similar in all groups except in premature infants, in whom it was slightly higher than it was in adults. The range of values was 0.29 to $0.36 \mathrm{mM}$. The concentration of sodium or potassium required to produce half-maximal activation of the stromal ATPase was the same in the four groups, 9.4 to $10.0 \mathrm{mM}$ for sodium and 0.82 to $1.10 \mathrm{mM}$ for potassium.

Reticulocytes were found to possess increased ATPase activity, but term infants with comparable reticulocyte counts showed the same total ATPase activity as normal adults.

Both term and premature infants were found to possess significantly less ouabain-sensitive membrane ATPase and thus less of the sodium-potassium activated membrane transport system than other cells of comparable reticulocyte count. Ouabain $\left(10^{-4} \mathrm{M}\right)$ produced a $60.1 \pm 4.8 \%$ inhibition of ATPase activity in adults and a $56.2 \pm 8.9 \%$ inhibition in subjects with reticulocy tosis. In contrast, ouabain produced an inhibition of only $43.1 \pm 6.4 \%$ in term infants and $39.3 \pm 6.3 \%$ in premature infants.

These findings suggest that neonate erythrocytes have a relative deficiency of membrane ATPase that is activated by sodium and potassium.

\section{Speculation}

That the erythrocytes of the newborn infant have less sodium-potassium activated stromal ATPase may be responsible for the increased potassium leak observed when these cells are incubated for short periods at $37^{\circ}$. This relative ATPase deficiency is another illustration that the erythrocytes of the newborn are metabolically different from those of normal adults, and this particular difference may play a central role in the shortened survival of the red cells of the newborn infant. Investigation of other neonatal tissues is warranted to obtain evidence of a generalized difference in cation transport during this period of life. 


\section{Introduction}

Previous studies $[19,24]$ have demonstrated that the erythrocytes of newborn infants lose potassium at an accelerated rate when stored at $4^{\circ}$ or when incubated at $37^{\circ}$. The normal red cell has an intracellular potassium concentration of approximately $100 \mathrm{mEq} / \mathrm{l}$ cells and a sodium concentration of $10 \mathrm{mEq} / \mathrm{l}$ cells. These concentrations are maintained by the active transport of potassium into the cell and the active transport of sodium out of the cell. The transport of these cations is dependent upon a series of pumps in the red cell membrane. The major source of energy for cation transport is adenosine triphosphate [7]. The ATPase activity of the stroma is closely correlated with its cation transport ability.

The characteristics of the red cell stromal ATPase were examined in newborn infants and contrasted with those observed in the stroma of normal adults and subjects with reticulocytosis to determine if this enzyme possessed different properties in the cells of the neonate that would explain the altered potassium metabolism.

\section{Materials and Methods}

\section{Subjects}

Blood samples were obtained from ten premature infants and sixteen term infants during the first twentyfour hours of life. All infants designated as premature weighed less than $2000 \mathrm{~g}$ at birth and their gestational ages did not exceed thirty-six weeks. Blood samples were also obtained from fourteen healthy adults and thirteen subjects with reticulocytosis. Among those with reticulocytosis were six patients with sickle cell disease, two with iron deficiency anemia, three with congenital nonspherocytic hemolytic anemia, one with hemoglobin-SC disease, and one with anorexia nervosa, under treatment. This group of ten children and three adults ranged in age from 5 months to 50 years. Blood samples were collected in tubes containing dried sodium heparin and processed within an hour of collection.

\section{Preparation of Stroma}

Red cell stroma mixture was prepared by the method of NAKAO et al. [12], a modification of the method of DODGE et al. [3]. The cells were washed three times in an isotonic sodium phosphate buffer, $\mathrm{pH}$ 7.4, and then resuspended in the same buffer to a hematocrit of $35-40 \%$. The cell suspension was then hemolyzed by the rapid addition of 15 volumes of ice cold Tris (hydroxymethyl) aminomethane buffer, $5 \mathrm{mM}, \mathrm{pH} 8.0$. The hemolysate was then centrifuged at $15,000 \times \mathrm{G}$ for 30 minutes in a RC-2 Sorvall refrigerated automatic centrifuge at $2^{\circ}$. The sediment was washed three times with 15 volumes of Tris buffer or until the supernatant fluid was colorless. The fluffy white sediment, the stroma, containing less than $0.1 \%$ hemoglobin as determined by the method of DODGe et al. [3] was carefully resuspended to its original packed cell volume in Tris buffer and was stored frozen until assayed. All assays were performed within 48 hours of stroma preparation since it was found that activity decreased markedly on storage beyond this time.

\section{ATPase Assay}

Stromal ATPase activity was assayed in an incubation system modified from that described by PARKER and Hofrman [15] and contained in a final volume of $2.6 \mathrm{ml}$ : Tris, pH 7.4, $20 \mu$ moles; magnesium chloride, $10 \mu$ moles; ethylene diamine tetracetic acid (EDTA), $0.5 \mu$ moles; adenosine triphosphate, $5 \mu$ moles; red cell stromal suspension, $0.5 \mathrm{ml}$; and varying concentrations of sodium and potassium as the chloride salts to a final concentration of $115 \mathrm{mM}$. The concentrations of sodium and potassium for determination of half-maximal activation studies were confirmed by an Instrumentation Laboratory flame photometer Model 143. The disodium salt of adenosine triphosphate was employed in all experiments except those in which the half-maximal activation of ATPase by sodium or magnesium-dependent ATPase was under investigation. In these latter experiments, the sodium-free Tris-ATP form was used. In experiments employing ouabain, the final concentration of ouabain in the incubation mixture was $1.9 \times 10^{-4} \mathrm{M}$.

The reaction was started by the addition of ATP and incubation was carried out at $37^{\circ}$ in a metabolic shaker at 72 oscillations per minute. At zero and one hundred and twenty minutes, $1-\mathrm{ml}$ aliquots were removed and deproteinized by the addition of $1 \mathrm{ml}$ of cold $10 \%$ trichloroacetic acid (TCA). Inorganic phosphate was determined in the supernatant by the method of Fiske and Subbarow [4].

Enzyme activity was expressed in millimicromoles (m $\mu$ moles) of phosphate liberated per hour per milligram of dry stroma or per milligram of stromal protein. Stromal weight was determined by drying one-half $\mathrm{ml}$ of stromal suspension in a previously weighed bottle to constant weight at $100^{\circ}$. Stromal protein was determined by the method of LOWRY [9].

\section{Km ATP Studies}

$\mathrm{Km}$ ATP (Michaelis constant for adenosine triphosphate by ATPase) was determined in a series of tubes, each with a total volume of $2.6 \mathrm{ml}$ containing $20 \mu$ moles Tris, $\mathrm{pH} 7.4 ; 0.5 \mu$ moles EDTA; $270 \mu$ moles sodium chloride; $20 \mu$ moles potassium chloride; membrane suspension, $0.5 \mathrm{ml}$; and varying dilutions of Tris-ATP in magnesium chloride, $0.1 \mathrm{ml}$. The dilu- 
tions of Tris-ATP in magnesium chloride varied from $0.1 \mathrm{M}$ Tris-ATP in $0.2 \mathrm{M}$ magnesium chloride to $0.003125 \mathrm{M}$ Tris-ATP in $0.00625 \mathrm{M}$ magnesium chloride. At zero and one hundred and twenty minutes, in a shaking incubator at $37^{\circ}, 1$-ml samples were removed, deproteinized by the addition of $1 \mathrm{ml}$ of cold $10 \%$ TGA, and these TCA extracts were analyzed for inorganic phosphate by the method described above. By the Lineweaver Burk formulation of double reciprocal plots, the apparent $\mathrm{Km}$ ATP was determined. It has been recently pointed out that for many regulatory enzymes at low substrate concentrations, the activation curve is sigmoid rather than first order [1]. With the concentrations of ATP used in our experiments, however, no allosteric effect was noted and $\mathrm{Km}$ ATP was retained as a useful kinetic parameter.

Magnesium-dependent ATPase activity was measured in $2.6 \mathrm{ml}$ of incubation medium containing magnesium chloride, $290 \mu$ moles; EDTA, $0.5 \mu$ moles; Tris, pH 7.4, $20 \mu$ moles; Tris-ATP, $5 \mu$ moles; stromal suspension, $0.5 \mathrm{ml}[25]$.

\section{Results}

Where applicable, results were expressed as mean \pm 1 $\mathrm{SD}$.

\section{Maximal Specific Activity}

The average maximal specific activity in fourteen adults was $296 \pm 60 \mathrm{~m} \mu$ moles $P_{i} / h / m g$ dry stroma; in sixteen term infants, $351 \pm 87$ mumoles; in ten premature infants, $573 \pm 154$ m moles; and in thirteen subjects with elevated reticulocyte counts, $563 \pm 173$ m $\mu$ moles (table I). The average reticulocyte counts in these groups were $0.9 \%$ in adults, $5.0 \%$ in term infants, $6.9 \%$ in premature infants, and $8.0 \%$ in patients with reticulocytosis. It is well recognized that ATPases pose unique problems in assay systems as they are membrane-bound. Consequently, changes in membrane components unrelated to ATPase might alter the activity of ATPase when expressed per unit weight of stroma. As a check on ATPase activity expressed per unit of weight, the ATPase activity was also expressed per $\mathrm{mg}$ of stromal protein. On expressing stromal ATPase in terms of $\mathrm{mg}$ of protein, similar differences persisted (table I). The distribution of maximal specific activity of ATPase in the four groups shows that adults and term infants have similar activities despite the higher reticulocyte counts of the latter. Premature infants, however, were similar to patients with higher reticulocyte counts.

\section{$K m A T P$}

From the activation curve for ATP of stromal ATPase (fig. 1), Km ATP was derived by the Lineweaver

Table $I$. Red cell stromal ATPase ${ }^{1}$

Adults Term infants Premature infants Subjects with
reticulocytosis

\begin{tabular}{|c|c|c|c|c|}
\hline $\begin{array}{l}\text { a) Total activity }\left(\mathrm{m} \mu \text { moles } \mathrm{P}_{\mathrm{i}} /\right. \\
\mathrm{h} / \mathrm{mg} \text { dry stroma) }\end{array}$ & $296 \pm 60(14)^{2}$ & $351 \pm 87(16)$ & $573 \pm 154(10)$ & $563 \pm 173(13)$ \\
\hline $\begin{array}{l}\text { b) Total activity (m } \mu \text { moles } \mathrm{P}_{\mathrm{i}} / \\
\mathrm{h} / \mathrm{mg} \text { protein) }\end{array}$ & $929 \pm 300(9)$ & $993 \pm 300(10)$ & $1746 \pm 374(8)$ & $1369 \pm 350(12)$ \\
\hline $\begin{array}{l}\text { c) Percent ouabain } \\
\text { inhibition }\end{array}$ & $60.1 \pm 4.8$ & $43.1 \pm 6.4$ & $39.3 \pm 6.3$ & $56.2 \pm 8.9$ \\
\hline $\begin{array}{l}\text { d) Ouabain-sensitive activity } \\
\text { (m } \mu \text { moles) } \mathrm{P}_{\mathrm{i}} / \mathrm{h} / \mathrm{mg} \text { dry } \\
\text { stroma) }\end{array}$ & $179 \pm 46$ & $152 \pm 44$ & $227 \pm 99$ & $327 \pm 100$ \\
\hline $\begin{array}{l}\text { e) Ouabain-insensitive } \\
\text { activity }(a-d)\end{array}$ & 117 & 199 & 346 & 236 \\
\hline f) Ratio: d/e & 1.51 & 0.75 & 0.65 & 1.28 \\
\hline $\begin{array}{l}\text { g) Potassium half-maximal } \\
\text { activation, mM }\end{array}$ & $1.1 \pm 0.38$ & $0.82 \pm 0.27$ & $0.97 \pm 0.20$ & $0.83 \pm 0.12$ \\
\hline $\begin{array}{l}\text { h) Sodium half-maximal } \\
\text { activation, } \mathrm{mM}\end{array}$ & $9.8 \pm 1.2$ & $10.96 \pm 1.6$ & $10.5(1$ infant $)$ & $9.4 \pm 1.7$ \\
\hline i) $\mathrm{Km}$ ATP, mM & $0.285 \pm 0.042$ & $0.287 \pm 0.061$ & $0.358 \pm 0.019$ & $0.339 \pm 0.069$ \\
\hline
\end{tabular}

1 Values are mean and SD of the mean.

${ }^{2}$ Numbers in parentheses refer to number of subjects. 


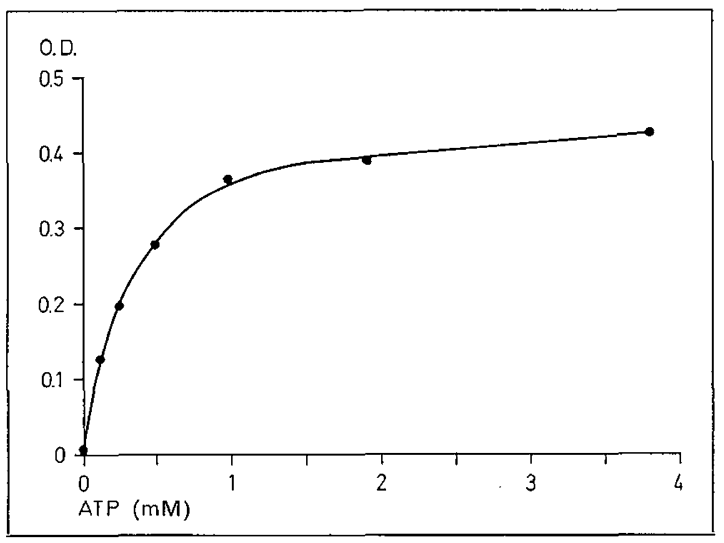

Fig. 1. Activation curve for ATP. See text for incubation conditions. This data was used to derive apparent Km ATP by Lineweaver Burk formulation of reciprocal plots shown on figure 2 .

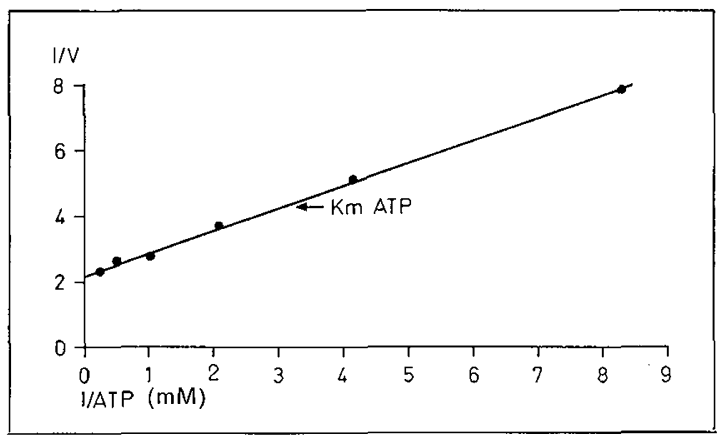

Fig.2. Lineweaver Burk plot for $\mathrm{Km}$ ATP of stromal ATPase. See method of Km ATP studies for incubation conditions.

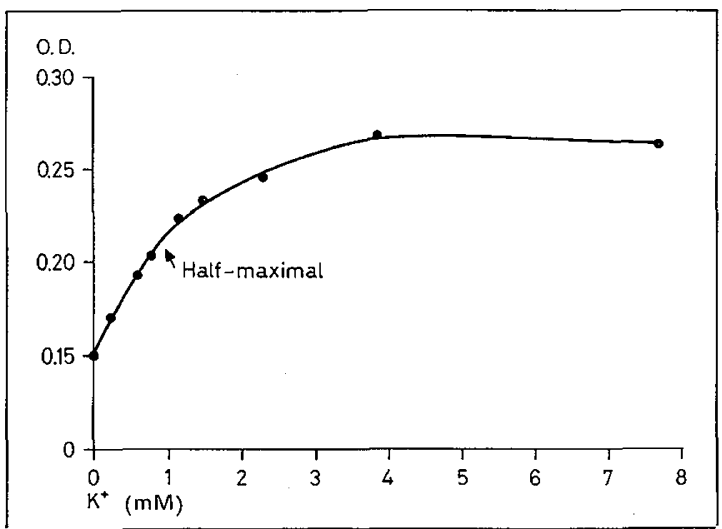

Fig. 3. The activation of stromal ATPase by increasing concentrations of potassium ion in the incubation medium. Note there is no further activation of ATPase by concentrations of potassium ion over $4 \mathrm{mM}$. See text for incubation conditions.
Burk formulation (fig. 2). The average value (mM) in adults was $0.285 \pm 0.042$; in term infants, $0.287 \pm$ 0.0612 ; in premature infants, $0.358 \pm 0.019$; and in patients with reticulocytosis, $0.339 \pm 0.069$ (table I). No significant difference was observed between adults, patients with reticulocytosis, and term infants $(p>0.1)$. Similarly, there was no significant difference between premature infants and patients with reticulocytosis $(p<0.5,>0.1)$; however, there was a significant difference between adults and premature infants $(p<0.01)$.

\section{Half-Maximal Activation by Potassium}

The average value for all groups was similar ( $p$ $>0.01$ ). Adults had a value of $1.1 \pm 0.38$; term infants, $0.82 \pm 0.27$; premature infants $0.97 \pm 0.20$ and patients with reticulocytosis, $0.83 \pm 0.12 \mathrm{mM}$. The effect on ATPase activity of varying the potassium ion concentration of a preparation of adult stroma (fig. 3) illustrates that increases in potassium ion above $4 \mathrm{mM}$ do not cause increased activation of sodium-potassium dependent ATPase. Similar curves were obtained with stromal ATPase of newborn infants and patients with reticulocytosis.

\section{Half-Maximal Activation by Sodium}

The average value for all groups was similar $(\mathrm{p}<0.5$, $>0.1$ ). The value for adults was $9.8 \pm 1.2$; for term infants, $10.96 \pm 1.6$; for premature infants, 10.5 (one infant); and for patients with reticulocytosis, $9.4 \pm 1.7$ $\mathrm{mM}$ (table I). Graphs such as figure 4, similar to those obtained for the half-maximal activation by potassium, were plotted to show the effect of increasing sodium concentration on activation of ATPase.

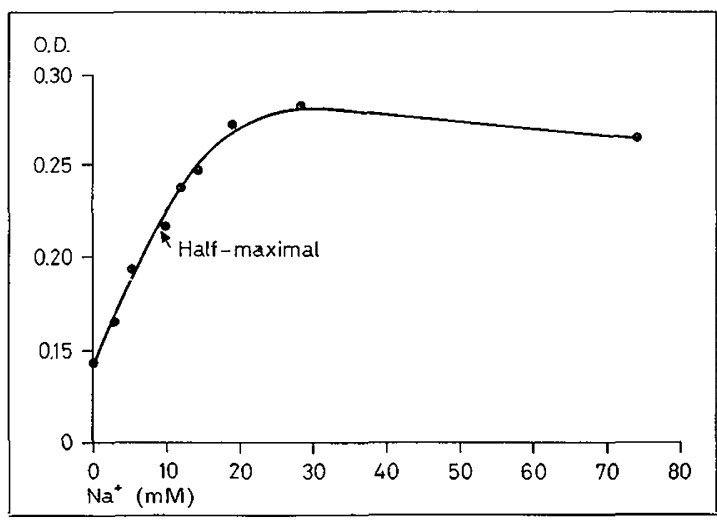

Fig.4. The activation of stromal ATPase by increasing concentrations of sodium ion in the incubation medium. 

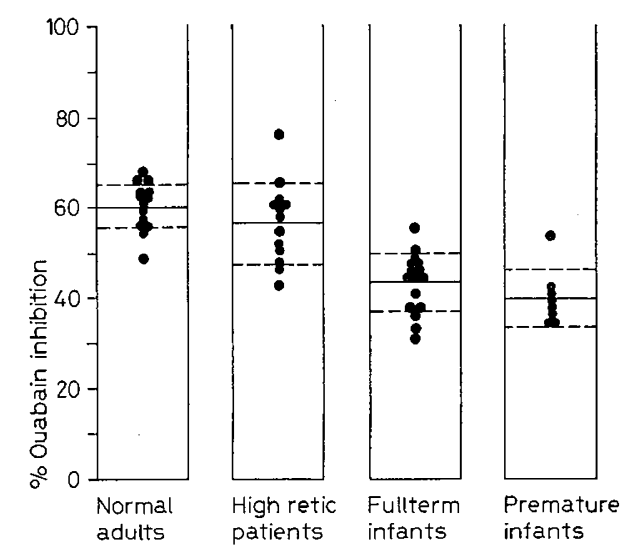

Fig. 5. The effect of ouabain on stromal ATPase activity. Ouabain causes a greater degree of inhibition of ATPase in adults and subjects with reticulocytosis than in newborn infants. Dotted lines indicate $\pm 1 \mathrm{SD}$; solid lines indicate means.

\section{Ouabain Effect}

The average ouabain inhibition of total ATPase activity was $60.1 \pm 4.8 \%$ in adults and $56.2 \pm 8.9 \%$ in patients with elevated reticulocyte counts. In contrast, the ouabain-sensitive ATPase was less in both groups of neonates. In term infants the ouabain-sensitive ATPase was $43.1 \pm 6.4 \%$ and in premature infants the average inhibition was $39.3 \pm 6.3 \%$. The distribution of ouabain inhibition for individuals in all four groups is shown in figure 5 . There was no significant difference between normal adults and patients with reticulocytosis or between term and premature infants $(p<0.1$, $>0.05$ ). When adults and premature infants or adults and term infants were compared, however, there was a significant difference $(\mathrm{p}<0.01)$. Similarly, the response of patients with reticulocytosis compared with that of either premature or term infants was statistically different $(p<0.01)$.

These differences between groups persisted when sodium-potassium-dependent ATPase was expressed in $m \mu$ moles $P_{i} / h / m g$ dry stroma. The average sodiumpotassium dependent ATPase activity was $179.5 \pm 45.8$ in adults and $152.0 \pm 43.7$ in term infants, whereas it was $327.3 \pm 100.3$ in patients with reticulocytosis and $227.0 \pm 99.0$ in premature infants. The difference between sodium-potassium dependent ATPase in patients with reticulocytosis and in term or premature infants was statistically significant $(p<0.01)$. Thus per unit weight of stroma, infants have less sodium-potassium-dependent ATPase than others with comparable reticulocyte counts.

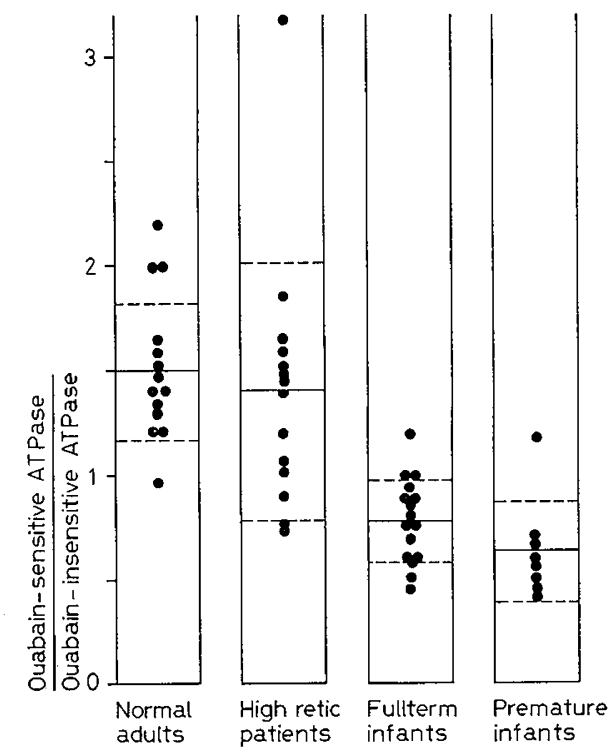

Fig.6. Ratio of ouabain-sensitive ATPase to ouabaininsensitive ATPase. Adults and subjects with reticulocytosis have higher ratios than newborn infants. Dotted lines indicate $\pm 1 \mathrm{SD}$, solid lines indicate means.

\section{Ratio of Sodium-Potassium-Sensitive ATPase to Magnesium- Dependent ATPase}

Average ratios of ouabain-sensitive, sodium-potassium-dependent ATPase to ouabain-insensitive, magnesium-dependent ATPase were 1.5 in adults, 1.41 in patients with reticulocytosis, 0.78 in term infants, and 0.64 in premature infants. These ratios (fig.6) again illustrate that newborn infants have an altered distribution of their sodium-potassium-sensitive pump to their magnesium-dependent pump when compared with normal adults or patients with reticulocytosis.

\section{Discussion}

Red cells in man, like certain tissues in many animal species, expend energy in maintaining transmembrane potentials and regulating cell volume. Anions and water are freely diffusible through the cell membrane but cations are selectively transported. Because animal cell membranes are permeable to sodium and potassium and do not obey the Gibbs-Donnan equilibrium, a dynamic balance in transport of these cations must be achieved so that in man, red cell potassium is maintained at approximately $100 \mathrm{mEq} / \mathrm{l}$ cells and red cell sodium at $10 \mathrm{mEq} / 1$ cells. Transport of these cations 
occurs by the sum of passive transport, a simple diffusion of cation, a 'leak' downhill from an area of high to an area of low electrochemical gradient, and active transport, a 'pump' uphill, requiring energy to move against a concentration and electrochemical gradient. The energy source for active transport in mammalian erythrocytes is glucose. Skou [20] first demonstrated the presence of an ATPase in crab nerve which hydrolyzed ATP to ADP and required the presence of both sodium and potassium ions for maximal activity. Post et al. [17] subsequently implicated red cell ATPase as an essential component in red cell active sodium and potassium transport. Recently, Hoffman [7] has identified two components to this cation pump in red cells and divided them into pumps I and II on the basis of ouabain sensitivity. Pump I requires ATP as substrate and is inhibited by ouabain. Pump $\mathrm{I}$ is further subdivided into Pump $\ \mathrm{~A}$, which requires potassium ion in the external medium, and Pump IB, which requires sodium ion in the external medium. Pump II is insensitive to ouabain and is sensitive to ethacrynic acid. Pump II requires sodium ion in the external medium. The substrate for Pump II is unknown. Pump I accounts for approximately $70 \%$ of the total cation flux and is the one studied here.

The active transport sodium-potassium-dependent pump in mammalian red cell membrane keeps the membrane functionally impermeable to these cations, thus providing volume stability. Recently it has been found that active transport in red cell membrane can affect the rate of cell metabolism: the ATP utilizing system activity influenced the ATP generating system [16]. When cellular sodium is high, inhibition of the pump by cardiac glycosides results in a concomitant reduction in the rate of glucose utilization and lactate formation to the basal level (i. e., low cellular sodium). The interaction between metabolism and active transport of sodium and potassium in red cells centers on membrane phosphoglycerate kinase, the substrate of which is compartmentalized ADP produced by the sodium-potassium-dependent ATPase.

Previously, YUNIs and AKIMURA [23], working with erythrocytes of rats and rabbits, showed there was a linear relation between the degree of reticulocytosis and ATPase activity. This was true for both total ATP. ase and the sodium-potassium-dependent portion, which are higher in reticulocytes, the younger red cells, than they are in mature red cells. We have found this observation to be valid for human erythrocytes as well. Subjects with reticulocytosis demonstrate increased ATPase activity in comparison with that of normal adults. Our studies indicate term infants have a relative deficiency of stromal ATPase for the average age of the red cells.

Total ATPase activity in adults was $351 \pm 87$ m $\mu$ moles $\mathrm{Pi} / \mathrm{h} / \mathrm{mg}$ dry stroma. This compares with the value of $390 \pm 134 \mathrm{~m} \mu$ moles reported by Post et al. [17] and the value $237 \pm 22 \mathrm{~m} \mu$ moles $\mathrm{Pi} / \mathrm{h} / \mathrm{mg}$ dry stroma for freshly prepared stroma reported by PARKer and Hoffman [15]. No values for newborn infants and patients with reticulocytosis were available for comparison.

Km ATP for adult stromal ATPase in this study averaged $0.285 \pm 0.042 \mathrm{mM}$. In one previous study [17], $\mathrm{Km}$ ATP was found to be $0.5 \mathrm{mM}$ for human erythrocytes. Perhaps differences observed in our study and in the previous study could be attributed to differences in method of enzyme preparation and incubation mixture for ATPase assay.

The requirements for potassium ion or sodium ion for half-maximal activation of stromal ATPase were found to be lower than previously published values. Whereas, in our studies, the half-maximal activation value was $9.8 \pm 1.2 \mathrm{mM}$ for sodium and $1.1 \pm 0.38 \mathrm{mM}$ for potassium for adult stromal ATPase, WHITTAM and AGER [22] reported values of 15 and $2.0 \mathrm{mM}$, respectively, and Post et al. [17] found values of 24 and $3.0 \mathrm{mM}$ for sodium and potassium activation, respectively.

Adult ghost inhibition by ouabain was $60.1 \pm 4.8 \%$ in our study. Parker and Hoffman [15] reported $46 \pm 22 \%$ inhibition in intact fresh ghosts and $59 \pm 21 \%$ in freeze-thawed ghosts. In one experiment, Post et al. [17] noted $50 \%$ ouabain inhibition of ATPase. In studies on other species [23], ouabain inhibited the ATPase of rabbit ghosts prepared in the manner of PARKER and HofFMAN [15] 80-90\%, whereas the ATPase of rat stroma was inhibited only $30-40 \%$. The degree of ouabain inhibition is affected by peculiarities of the membrane of various species as well as by the method of stroma preparation. It has been reported that pre-incubation with $30 \mathrm{mM}$ Tris buffer [8] increases the ouabain-sensitive portion of ATPase and that freeze-thawing stroma increases the maximal specific activity [18].

Premature infants when compared with adults had a significantly higher Km ATP. Young cells may possess a stromal ATPase with a higher Km ATP. The mean $\mathrm{Km}$ ATP in the subjects with reticulocytosis was higher than that in adults, but because of the variability in results, the heterogeneity of the group, and the small number of subjects studied, these differences could not be demonstrated to be statistically significant. This question remains unanswered.

In newborn infants, both premature and full term, there was a relative and total deficiency of stromal sodium-potassium-dependent ATPase (ouabain-inhibitable) compared with subjects having elevated reticulocyte counts. The observation is of note if one considers that sodium-potassium-dependent ATPase nor- 
mally is responsible for approximately $70 \%$ of cation flux.

The red cells of the newborn show morphologic, chemical, and immunological differences compared with those of the adult. Electron microscopy has revealed that neonatal red cells are structurally different [5]. Adult red cells appeared regular in shape with uniform cell walls and cytoplasm free of vacuoles. In contrast, neonatal red cells showed frequent vacuoles immediately beneath the cell wall, and these occasionally contained internal structures thought to be remnants of cristae of mitochondria. By chemical analysis, the neonatal membrane has the same total phospholipid content but possesses more sphingomyelin and less lecithin than the adult membrane [2].

From an immunological standpoint, neonatal cells are also different. At birth, the Lewis system of absorbed serum antigens is incompletely developed, partly because the receptor sites of the erythrocyte membrane are absent or weak at birth [11]. In the $\mathrm{ABO}$ system, the $\mathrm{A}$ and $\mathrm{B}$ antigen sites are thought to be incompletely expressed in the neonatal red cell [10] and likewise in the Ii system, the I antigen is weakly developed at birth.

The storage characteristics of neonatal red cells show further differences. Neonatal cells have increased osmotic fragility [19], increased mechanical fragility, and undergo abnormal forms more easily when stored or incubated [13]. In addition, they have been found to leak potassium at increased rates on storage at $4^{\circ}$ [19] or when incubated at $37^{\circ}$ [24]. This increased leak is not compensated by an increased rate of pumping so that the cells have a greater degree of spontaneous hemolysis.

Our observations that neonatal cells possess a relative and absolute deficiency of stromal ATPase of the sodium-potassium-dependent type, when compared with those of subjects with similar reticulocyte counts, may be reflected in the shorter red cell life span and the failure of the pump function to regulate cell volume and cell metabolism, particularly when stressed. It has previously been shown that cells of infants possess increased levels of ATP that decline rapidly on short incubation and that inorganic phosphate is very slowly incorporated into ATP [24].

Further studies are warranted to determine whether ouabain insensitivity of neonatal tissue is limited to erythrocyte membrane alone or whether the red cell membrane is only one of many tissues with ATPase activity affected. Cardiac and renal tissues, for example, may also be affected. The digitalizing dose per unit weight is higher in neonates than in adults, and the neonatal kidney cannot excrete high solute loads. Our observations implicate ATPase as a possible key to differences in membrane function during this period of life.
Summary

Red cell ATPase was examined in newborn infants and in adults, and as controls for the infants, in patients with elevated reticulocyte counts. Term infants showed no greater activity than adults with respect to maximal specific activity of ATPase. The properties of stromal ATPase, the requirements for sodium and potassium for half-maximal activation of the enzyme, appeared similar in all groups. $\mathrm{Km}$ ATP, however, was higher in premature infants than in term infants or adults.

Both term and premature infants possessed significantly less per cent ouabain-sensitive active transport ATPase than adults or patients with comparable reticulocyte counts. In the newborn, the relative insensitivity of red cells to the inhibitory effects of ouabain and the increased proportion of magnesium-dependent ATPase may be one manifestation of a generalized condition in all tissues concerned with the active transport of sodium and potassium. The relative and absolute deficiency of sodium-potassium-dependent ATPase in the newborn red cell may be another parameter for describing differences in adult and newborn red cells. Previous data showing differences in membrane structure, chemistry, metabolism, and blood antigens further emphasize the dissimilarity between adult and newborn erythrocytes.

It is suggested that this ATPase deficiency may play a role in the shortened life span of red cells in the newborn.

\section{References and $\mathcal{N}$ otes}

1. Atkinson, D.E.: Regulation of enzyme activity. Ann. Rev.Biochem. 35: 85 (1966).

2. Crowley, J. and Ways, P.: Fetal RBG lipids. Clin. Res. 12: 222 (1964).

3. Dodge, J.T.; Mrtahell, G. and Hanahan, D.J.: The preparation and chemical characteristics of hemoglobin-free ghosts of human erythrocytes. Arch. Biochem. 100: 119 (1963).

4. Fiske, G.H. and Subbarow, Y. : The colorimetric determination of phosphorus. J. biol. Ghem. 66: 375 (1925).

5. Haberman, S.; Blanton, P. and Martin, J. : Some observations on the $\mathrm{ABO}$ antigen sites of the erythrocyte membranes of adults and newborn infants. J. Immunol. 98: 150 (1967).

6. Hoffman, J.F.: Cation transport and structure of red cell plasma membrane. Circulation 26: 1201 (1962).

7. Hoffman, J.F.: The red cell membrane and the transport of sodium and potassium. Amer.J. Med. 41: 666 (1966). 
8. Hokin, L.E. and REASA, D. : Effects of preincubation of erythrocyte ghosts on ouabain-sensitive and ouabain-insensitive ATPase. Biochim. biophys. Acta 90: 176 (1964).

9. Lowry, O.; Rosebrough, N.J.; FARR, A.L. and Randall, R.J.: Protein measurement with the Folin phenol reagent. J.biol. Chem. 193: 265 (1951).

10. Mollison, P. L.: Blood transfusion in clinical medicine, p. 240 (Blackwell, Oxford 1967).

11. Mollison, P.L.: Blood transfusion in clinical medicine, p. 275 (Blackwell, Oxford 1967).

12. NaKaO, K.; Kurashina, S. and NakaO, M.: Adenosine triphosphatase activity of erythrocyte membrane in hereditary spherocytosis. Life Sci. 6: 595 (1967).

13. Oski, F.A.: The metabolism of erythrocytes and its relation to hemolytic anemias in the newborn. Pediat. Clin. N. Amer. 12: 687 (1965).

14. Oski, F. A. and Narman, J. L.: Red cell metabolism in the premature infant. Pediatrics 36: 104 (1965).

15. Parker, J. C. and Hoffman, J. F.: Failure to find increased sodium, potassium-ATPase in red cell ghosts of schizophrenics. Nature, Lond. 201: 823 (1964).

16. Parker, J.C. and Hoffman, J.F.: The role of membrane phosphoglycerate kinase in the control of glycolytic rate by active cation transport in human red blood cells. J.gen. Physiol. 50: 893 (1967).

17. Post, R.L.; Merritt, G.R.; Kinsolving, G.R. and Albright, C.D.: Membrane adenosine triphosphatase as a participant in the active transport of sodium and potassium in the human erythrocyte. J. biol. Chem. 235: 1796 (1960).

18. Scharff, O. and VestergaArd-Bogind, B.: Activation by freezing of the adenosine triphospha- tase-hydrolyzing enzyme system in human red cell membranes. Scand. J.clin. Lab. Invest. 18: 86 (1966).

19. SJöLIN, S.: The resistance of red cells in vitro. A study of the osmotic properties, the mechanical resistance and the storage behavior of red cells of fetuses, children and adults. Acta paediat. scand. suppl. 43: 98 (1954).

20. Skou, J.C.: The influence of some cations on an adenosine triphosphatase from peripheral nerves. Biochim. biophys. Acta 23: 394 (1957).

21. Skou, J. C.: Studies on the $\mathrm{Na}+$ and $\mathrm{K}+$ activated ATP hydrolyzing enzyme system. The role of SH groups. Biochem. Biophys. Res. Commun. 10: 79 (1963).

22. Whittam, R. and Ager, M.E.: The connexion between active cation transport and metabolism in erythrocytes. Biochem.J. 97: 214 (1965).

23. Yunis, A. and Aximura, G.: Sodium-potassiumdependent adenosine triphosphatase of mammalian reticulocytes and mature red blood cells. Proc. Soc. exp. Biol., N.Y. 121: 327 (1966).

24. Zipursky, A.; La Rue, T. and Israels, L. G.: The in vitro metabolism of erythrocytes from newborn infants. Canad.J. Biochem. 38: 727 (1960).

25. Disodium ATP, Tris-ATP, and Tris (hydroxymethyl) aminomethane (Trizma base) were obtained from Sigma Chemical Company; ouabain was obtained from Calbiochem Company.

26. Supported in part by Public Health Graduate Training Grant T1AM 5228 and by HD 01919. Dr. Oskr is a recipient of Research Career Development Award K03-HD-38600.

27. Requests for reprints should be addressed to: Frank A. Oski, M.D., Department of Pediatrics, Hospital of the University of Pennsylvania, Philadelphia, Pa. 19104 (USA). 